\title{
Allogeneic and autologous stem cell transplantation with busulfan, cyclophosphamide, and etoposide conditioning therapy for relapsed/refractory non-Hodgkin lymphoma
}

\author{
Neelima Vidula ${ }^{1^{*}}$, Andrew M. Evens $^{2^{*}}$, Irene B. Helenowski ${ }^{3}$, Borko Jovanovic ${ }^{3}$, \\ Jane N. Winter ${ }^{4}$, Jayesh Mehta ${ }^{4}$, Seema Singhal ${ }^{4}$, Stephanie F. Williams ${ }^{4}$, \\ Olga Frankfurt ${ }^{4}$, Jessica K. Altman ${ }^{4}$, Joanne Monreal ${ }^{4}$, Leo I. Gordon ${ }^{4 \#}$ \\ ${ }^{1}$ Division of Hematology-Oncology, University of California, San Francisco, USA \\ ${ }^{2}$ Division of Hematology-Oncology, The University of Massachusetts Medical School, Worcester, USA \\ ${ }^{3}$ Department of Preventive Medicine, Northwestern University, Chicago, USA \\ ${ }^{4}$ Division of Hematology-Oncology, Northwestern University, Chicago, USA; \\ \#Corresponding Author: 1-gordon@,northwestern.edu
}

Received 10 September 2013; revised 15 October 2013; accepted 21 October 2013

Copyright (C) 2013 Neelima Vidula et al. This is an open access article distributed under the Creative Commons Attribution License, which permits unrestricted use, distribution, and reproduction in any medium, provided the original work is properly cited.

\begin{abstract}
The optimal stem cell transplantation (SCT) conditioning therapy for relapsed/refractory nonHodgkin lymphoma (NHL) is not clearly defined. In a retrospective analysis, we examined 25 patients with "high risk" relapsed/refractory NHL who received busulfan, cyclophosphamide, and etoposide (Bu/Cy/VP16) conditioning with autologous or allogeneic SCT. The majority of patients had aggressive histology and $52 \%$ had primary refractory NHL. Furthermore, $48 \%$ of patients had chemotherapy-resistant disease at the time of SCT. Fifty-six percent of patients underwent allogeneic SCT, while $44 \%$ had autologous SCT. The median engraftment time for neutrophils and platelets was 13.5 and 14 days, respectively. The 100-day treatment-related mortality (TRM) was $16 \%$, while the 2-year non-relapse mortality (NRM) rate was also $16 \%$. At a median follow-up of $\mathbf{1 5}$ months, the estimated 2year disease-free survival (DFS) rate was $64 \%$ (95\% confidence interval ( $\mathrm{Cl}): 36 \%-82 \%$ ) and the estimated 2-year overall survival (OS) was $69 \%$ (95\% Cl: 40\% - 86\%). Furthermore, the 2-year disease-specific survival (DSS) rate was $73 \%(95 \%$ Cl: $40 \%-90 \%)$. Using Cox proportional hazard modeling, the International Prognostic Index at time of relapse predicted DFS and OS. Altogether, Bu/Cy/VP16 was associated with early TRM;

*Authors contributed equally.
\end{abstract}

however, late toxicities (including NRM) were uncommon resulting in relatively good survival rates in a high-risk relapsed/refractory NHL population.

Keywords: Stem Cell Transplantation; Busulfan; Cyclophosphamide; Etoposide; Non-Hodgkin Lymphoma

\section{INTRODUCTION}

Stem cell transplantation (SCT) is an effective therapeutic modality for patients with relapsed or refractory non-Hodgkin lymphoma (NHL) [1-5]. The timing and type of SCT (i.e., autologous or allogeneic) depends in part on disease histology, disease status (i.e., relapsed vs. refractory), patient physical condition, and disease-specific prognostic and other risk factors. A number of SCT chemotherapy conditioning regimens have been studied in relapsed/refractory NHL; however, the optimal conditioning regimen is not clearly defined.

Busulfan, cyclophosphamide, and etoposide $(\mathrm{Bu} / \mathrm{Cy} /$ VP16) have been investigated as a SCT conditioning regimen [6-12]. The outcomes of prior studies, however, have been quite variable with 3-year progression-free survival (PFS) rates ranging from $39 \%$ to $70 \%$ and 3 -year overall survival (OS) rates ranging from $43 \%$ to $72 \%[8,10]$. Furthermore, there are few $\mathrm{Bu} / \mathrm{Cy} / \mathrm{VP} 16$ studies that have been reported in the past $5-10$ years as supportive care treatments, and understanding of SCT has improved over the past decade. Also, an improved 
understanding of the complications associated with $\mathrm{Bu} /$ $\mathrm{Cy} / \mathrm{VP}-16$ is needed, especially as the early treatmentrelated mortality (TRM) with this regimen may be as high as $46 \%$ [13].

We analyzed the Northwestern experience with utilizing $\mathrm{Bu} / \mathrm{Cy} / \mathrm{VP} 16$ conditioning therapy for patients with relapsed/refractory NHL. Notably, this conditioning regimen was reserved at our institution for patients with high-risk disease (e.g., short initial remission, high IPI at relapse, chemotherapy-resistant disease at SCT, etc.). We examined detailed patient and disease characteristics, patient outcomes, and analyzed potential prognostic factors that predicted survival with $\mathrm{Bu} / \mathrm{Cy} / \mathrm{VP} 16 \mathrm{SCT}$.

\section{MATERIALS AND METHODS}

\subsection{Study Design}

We performed a retrospective analysis of all relapsed/ refractory NHL patients who received stem cell transplantation with $\mathrm{Bu} / \mathrm{Cy} / \mathrm{VP} 16$ conditioning chemotherapy at the Northwestern University Robert H. Lurie Comprehensive Cancer Center from 3/2003 to 6/2011. This study was approved by the Northwestern University Institutional Review Board. Relapsed disease was defined as disease that recurred following a response to initial therapy (lasting $>6$ months), while refractory disease was defined as disease that did not respond to therapy or relapsed within 6 months of remission. Patients who had received prior SCT were excluded from the analysis. Detailed patient characteristics were collected including patient age, gender, co-morbidities, baseline pulmonary (diffusing capacity for carbon monoxide (DLCO) and presence of obstructive or restrictive defects on pulmonary function testing), liver (liver enzymes), and cardiac function (ejection fraction and diastolic function on echocardiographic evaluation), and performance status. Furthermore, detailed disease characteristics at the time of relapse prior to SCT were examined including disease histology, chemotherapy sensitivity, number of extranodal sites, disease stage, number of prior chemotherapy regimens, history of prior radiation, LDH immediately before transplant after salvage therapy (pre-SCT LDH), presence of bulk disease $(>10 \mathrm{~cm})$, International Prognostic Index (IPI), and disease status at time of SCT.

\subsection{Preparative Regimen}

Busulfan was dosed at $3.2 \mathrm{mg} / \mathrm{kg}$ intravenous (IV) daily for 4 days on days -8 to -5 , etoposide was dosed at $20-40 \mathrm{mg} / \mathrm{kg}$ (most commonly $30 \mathrm{mg} / \mathrm{kg}$ ) IV for one day on day -4 , and cyclophosphamide was dosed at 50 $\mathrm{mg} / \mathrm{kg}$ IV daily for 2 days on days -3 and -2 (all based on ideal body weight). Granulocyte colony stimulating factor (G-CSF), dosed at $5 \mu \mathrm{g} / \mathrm{kg}$, was started on day 5 for autologous SCTs. Dilantin seizure prophylaxis was given with chemotherapy infusion and all patients received ciprofloxacin for prophylaxis prior to conditioning therapy, and bactrim, acyclovir, and diflucan prophylaxis on discharge after transplant. Patients who received allogeneic SCT received graft versus host disease (GVHD) prophylaxis with a calcineurin inhibitor and methotrexate.

\subsection{Statistical Analysis}

Engraftment time was defined as the time to an absolute neutrophil count (ANC) $>500 / \mu \mathrm{L}$ for 3 consecutive days and a platelet count $>20,000 / \mu \mathrm{L}$ post-SCT without requiring a transfusion. Toxicity post transplant was graded according to the National Cancer Institute Common Terminology Criteria (NCI CTC) scale. Early toxicity was defined as adverse events occurring less than 100 days post-transplant, whereas late toxicity was defined as adverse events occurring $\geq 100$ days post-transplant. Allogeneic SCT patients were also evaluated for the presence of GVHD in the acute ( $<100$ days) and chronic ( $\geq 100$ days) post-SCT period.

Overall survival (OS), disease-free survival (DFS), and disease-specific survival (DSS) curves were constructed using the Kaplan-Meier method. OS was defined as survival after transplant. DFS was defined as survival in complete remission (complete clinical and radiographic resolution of tumor). DSS was defined as survival from disease post SCT. Univariate proportional hazard modeling was performed to determine which patient and disease characteristics as described above might be associated with survival outcomes. Logrank tests were used to compare survival rates and the Wald chi-square test was used to determine the significance of model coefficients from the Cox regression, which was in turn used to determine the effect of various factors on survival. Fisher's exact test was used to examine the association between toxicity outcomes and categorical patient and disease characteristics, while the Wilcoxon rank-sum test was used to examine the association between toxicity outcomes and continuous patient and disease characteristics. For all analyses, $\mathrm{p}<0.05$ was considered statistically significant.

\section{RESULTS}

\subsection{Patient Demographics}

Twenty-five patients with relapsed or refractory NHL underwent SCT with $\mathrm{Bu} / \mathrm{Cy} / \mathrm{VP} 16$ conditioning from 3/ 2003 to $6 / 2011$. The demographics of the study population and the associated disease characteristics are summarized in Table 1.

The majority of patients (76\%) had aggressive NHL histology. All patients had relapsed or refractory disease. 
Furthermore, $52 \%$ of patients had primary refractory lymphoma. The median number of prior regimens was 3 . In terms of disease status at time of SCT (i.e., response to salvage therapy), $52 \%$ of patients had chemotherapy sensitive disease $(n=11$ complete remission and $n=2$ partial remission), while $48 \%$ had chemotherapy resistant disease $(n=12$ progressive disease).

\subsection{Engraftment, Toxicity, and Transplant Related Mortality (TRM)}

The median engraftment time for neutrophils and platelets were 13.5 and 14 days, respectively. In terms of SCT-related toxicity, 92\% patients experienced grade 3 or 4 hematologic toxicity. The most common grade 3 or 4 non-hematologic toxicities were neutropenic fever $(92 \%)$, infection $(68 \%)$, pneumonitis $(28 \%)$, intubation $(16 \%)$, and altered mental status/stroke $(12 \%)$ in the early post-transplant period (Table 2). In the late posttransplant period, $44 \%$ of patients experienced pneumonitis (Table 2). The most common grade 1 - 2 toxicities in the early post-transplant period were elevated liver enzymes $(72 \%)$ and mucositis $(64 \%)$ followed by renal failure $(8 \%)$, hypersensitivity reaction $(8 \%)$, and thromboembolism (4\%).

In the initial post-transplant period (i.e., <100 days), 4 of 25 patients died from hypoxemic respiratory failure (3) and sepsis (1) yielding a TRM of $16 \%$. Two of these patients had allogeneic SCT (diffuse large B-cell lymphoma (DLBCL) and acute lymphoblastic lymphoma), while the other two had received autologous SCT (both DLBCL) yielding TRM rates of $14 \%$ and $18 \%$ for allogeneic and autologous patients, respectively.

Among patients who received allogeneic SCT, 11/14 (79\%) experienced acute GVHD, with skin and liver involvement being the most frequent organs involved. After 100 days post-SCT, 6/11 (55\%) patients experienced chronic GVHD most commonly affecting the skin. Notably, there were no non-relapse deaths that occurred after 100 days post-SCT in either the autologous or allogeneic population; thus, the 2-year NRM for all patients was $16 \%$ with all of these deaths occurring $<100$ days.

\subsection{Survival}

The median follow-up time for all patients was 15 months (range: 2 - 96 months). The 1-year and 2-year DFS rates for all patients (Figure 1) were 73\% (95\% confidence interval (CI): $64 \%-87 \%$ ) and 64\% (95\% CI: $36 \%-82 \%$ ), respectively, while the 1-year and 2-year OS rates were $79 \%$ (95\% CI: 57-91\%) and 69\% (95\% CI: $40 \%-86 \%$ ), respectively (Figure 1). Of note, only 2 of $25(8 \%)$ patients died due to NHL. This resulted in a 2-year disease-specific survival (DSS) for all patients of

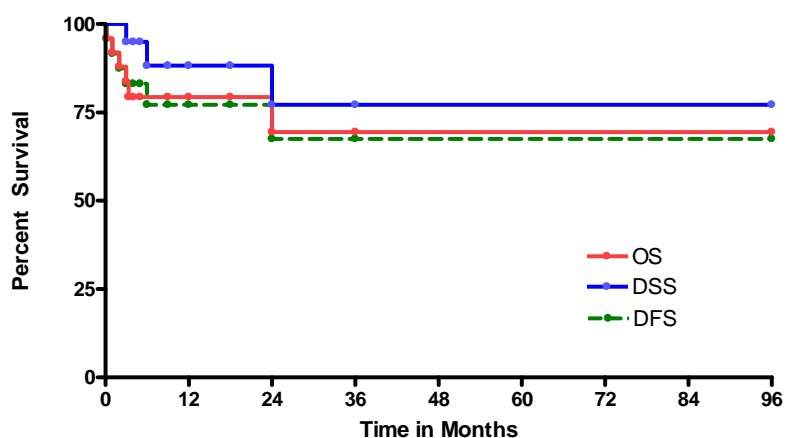

Figure 1. Overall Survival (OS), Disease Specific Survival (DSS) and Disease Free Survival (DFS). The 1 year rate of OS was $79 \%(95 \%$ CI: $57 \%-91 \%)$ and the 2 year rate of OS was $69 \%$ (95\% CI: $40 \%-86 \%)$. The 1 year rate of DSS was $83 \%$ (95\% CI: $56-94 \%)$ and the 2 year rate of DSS was $73 \%(95 \%$ CI: $40 \%-90 \%)$. The 1 year rate of DFS was $73 \%(95 \% \mathrm{CI}$ : $64 \%-87 \%$ ) and the 2 year rate of DFS was $64 \%$ (95\% CI: $36 \%$ $-82 \%)$.

73\% (95\% CI: 40\% - 90\%) (Figure 1). For allogeneic patients, OS was $86 \%$ at 1 year and $75 \%$ at 2 years, whereas for autologous patients, OS was $72 \%$ at 1 year (OS could not be calculated at 2 years due to the followup period).

\subsection{Prognostic Factors}

Proportional hazard modeling of multiple patient characteristics and disease factors were examined for all patients to identify potential factors that predicted survival using a univariate analysis (Table 3 ). We identified that elevated pre-SCT LDH (hazard ratio (HR) 8.1, 95\% CI: $1.4-45.2, p=0.02)$ and IPI at time of relapse prior to SCT (HR 3.0, 95\% CI 1.1 - 7.9, p = 0.03) portended inferior DFS, while increasing age (HR 1.1, 95\% CI: $1.0-1.1, \mathrm{p}=0.06$ ), chemotherapy-resistant disease (HR 7.73, 95\% CI: $0.93-64.5, \mathrm{p}=0.07)$, and performance status prior to SCT (HR 6.5, 95\% CI: 0.8 - 53.8, p = $0.08)$ were of borderline significance. Elevated pre-SCT LDH (HR 15.0, 95\% CI: $1.6-138.1, \mathrm{p}=0.02$ ) and IPI (HR 4.4, 95\% CI: $1.5-13.1, \mathrm{p}=0.008$ ) also predicted inferior OS, while worse performance status (HR 3.74, 95\% CI: 0.99 - 14.0, p = 0.05), age (HR 1.1, 95\% CI $1.0-1.2, \mathrm{p}=0.06)$, and chemotherapy-resistant disease (HR 6.54, 95\% CI: $0.76-56.3, \mathrm{p}=0.09$ ) were borderline.

Fisher's exact test and Wilcoxon rank sum test analysis were performed to examine patient and disease characteristics that correlated with late toxicity. The strongest predictors of post-SCT late toxicity were pre-transplant LDH $(p=0.057)$ and IPI $(p=0.11)$. Finally, late toxicity was more likely to be associated with aggressive NHL disease histology (61\%) compared with low grade $(31 \%)$ or mixed histologies $(8 \%)$. 
Table 1. Patient demographics and disease characteristics.

\begin{tabular}{|c|c|}
\hline Criteria & Description \\
\hline \multirow[t]{2}{*}{ Age } & Median: 49 \\
\hline & Range: 27 - 71 \\
\hline \multirow[t]{2}{*}{ Sex } & Male: $16 / 25(64 \%)$ \\
\hline & Female: $9 / 25(36 \%)$ \\
\hline \multirow[t]{3}{*}{ Histology } & Low grade (5 FL and 1 MZL 6/25 (24\%) \\
\hline & $\begin{array}{l}\text { Aggressive (9 DLBCL, } 3 \text { MCL, } 2 \text { transformed DLBCL), } 1 \text { Richter's transformation } \\
\text { (i.e., CLL to DLBCL), } 1 \text { precursor B-cell ALL): } 16 / 25(64 \%)\end{array}$ \\
\hline & Mixed histology (i.e., 2 NHL and HL and 1 DLBCL and FL): 3/25 (12\%) \\
\hline \multirow[t]{2}{*}{ Extra-nodal sites } & Median: 2 \\
\hline & Range: 0 - 7 \\
\hline \multirow[t]{5}{*}{ Disease stage } & Median: 4 \\
\hline & Range: 2 - 4 \\
\hline & Stage $2: 3 / 25(12 \%)$ \\
\hline & Stage 3: 7/25 (28\%) \\
\hline & Stage 4: 15/25 (60\%) \\
\hline \multirow[t]{2}{*}{ Disease status $^{*}$} & Primary refractory: $13 / 25(52 \%)$ \\
\hline & Relapsed disease: $12 / 25(48 \%)$ \\
\hline \multirow[t]{2}{*}{ Remission period prior to SCT (for those patients in remission) } & Median: 4 months \\
\hline & Range: 2 - 12 months \\
\hline \multirow[t]{2}{*}{ Performance Status } & Median: 1 \\
\hline & Range: 0 - 2 \\
\hline \multirow[t]{3}{*}{ LDH immediately prior to SCT (pre-SCT LDH) } & Normal: 16/25 (64\%) \\
\hline & 1 - 3 times normal: $8 / 25(32 \%)$ \\
\hline & $\geq 3$ times normal: $1 / 25(4 \%)$ \\
\hline \multirow[t]{6}{*}{ IPI } & $0: 1 / 25(4 \%)$ \\
\hline & $1: 2 / 25(8 \%)$ \\
\hline & $2: 13 / 25(52 \%)$ \\
\hline & 3: $6 / 25(24 \%)$ \\
\hline & $4: 3 / 25(12 \%)$ \\
\hline & Median: 2 \\
\hline \multirow[t]{2}{*}{ Prior regimens } & Median: 3 \\
\hline & Range: 1 - 7 \\
\hline \multirow[t]{2}{*}{ Prior radiation } & Yes: 4/25 (16\%) \\
\hline & No: $21 / 25(84 \%)$ \\
\hline \multirow[t]{2}{*}{ Bulky adenopathy } & Yes: 4/25 (16\%) \\
\hline & No: $21 / 25(84 \%)$ \\
\hline
\end{tabular}




\section{Continued}

Comorbidities

Yes: $22 / 25(88 \%)$

No: $3 / 25(12 \%)$

Number of patients with various comorbidities:

Cardiac disease: $2 / 25(8 \%)$

Diabetes: $4 / 25(16 \%)$

Hyperlipidemia: 3/25 (12\%)

Hypertension: 10/25 (40\%)

Prior cancer: 6/25 (24\%)

Pulmonary disease: 5/25 (20\%)

Psychiatric: 8/25 (32\%)

Renal disease: $4 / 25(16 \%)$

Thromboembolism: 3/25 (12\%)

Other including rheumatologic/neurologic disease: 12/25 (48\%)

Baseline pulmonary status

Baseline liver function

Baseline cardiac function

Disease/chemotherapy sensitivity (at time of SCT)

Type of SCT
Normal: 12/25 (48\%)

Decreased DLCO or obstructive/restrictive defect: 13/25 (52\%)

Normal: 19/25 (76\%)

Elevated liver function tests: 6/25 (24\%)

Normal: $13 / 25(52 \%)$

Depressed EF ( $<50 \%)$ or diastolic dysfunction: 12/25 (48\%)

Sensitive: $13 / 25(52 \%)$

Resistant: 12/25 (48\%)

Allogeneic: $14 / 25(56 \%)$

Autologous: 11/25 (44\%)

Abbreviations: FL, follicular lymphoma; MZL, marginal zone lymphoma; DLBCL, diffuse large B-cell lymphoma; MCL, mantle cell lymphoma; NHL, Non-Hodgkin lymphoma; CLL, chronic lymphocytic leukemia; ALL, acute lymphoblastic leukemia; HL, Hodgkin lymphoma; IPI, International Prognostic Index; DLCO, diffusing capacity for carbon monoxide; EF, ejection fraction; SCT, stem cell transplant. ${ }^{*}$ Primary refractory disease indicates no remission to prior therapy or remission duration $<6$ months.

Table 2. Early and late SCT-related grade 3 and 4 toxicities.

\begin{tabular}{ccc}
\hline Toxicity & Early $^{*}$ & Late $^{*}$ \\
\hline Neutropenic fever & $23 / 25(92 \%)$ & None \\
Infection & $17 / 25(68 \%)$ & $3 / 18(17 \%)$ \\
Pneumonitis & $7 / 25(28 \%)$ & $8 / 18(44 \%)$ \\
Intubation & $4 / 25(16 \%)$ & None \\
Altered mental status or stroke & $3 / 25(12 \%)$ & $1 / 18(5.6 \%)$ \\
Renal failure & $2 / 25(8 \%)$ & None \\
Cardiac complication & $2 / 25(8 \%)$ & None \\
\hline
\end{tabular}

*Early indicates 1 - 99 days post-SCT, while late indicates $\geq 100$ days postSCT.

\section{DISCUSSION}

Stem cell transplantation has become a treatment option for NHL patients including those with relapsed/ refractory disease, low, intermediate or high grade NHL, and aggressive NHL [1-6,9-10,12,14-19]. For relapsed/ refractory $\mathrm{NHL}, \mathrm{Bu} / \mathrm{Cy} / \mathrm{VP}-16$ has been investigated as a conditioning regimen. We retrospectively analyzed the efficacy and toxicity of this regimen at the Northwestern University Robert H. Lurie Comprehensive Cancer Center for patients with "high risk" relapsed or refractory NHL.

Results of our study support data from prior studies suggesting that $\mathrm{Bu} / \mathrm{Cy} / \mathrm{VP}-16$ is an effective conditioning regimen prior to $\mathrm{SCT}$ in patients with relapsed/refractory NHL. We noted a 2-year OS rate of $69 \%$ and 2-year DFS rate of $64 \%$ in a relatively high risk NHL patient population. These data are similar to results obtained by Kim et al. [10] who estimated the 3-year OS and PFS for relapsed/refractory or high-risk NHL patients transplanted with $\mathrm{Bu} / \mathrm{Cy} / \mathrm{VP}-16$ to be $72 \%$ and $70 \%$, respectively, with $61 \%$ of patients in complete remission and $39 \%$ of patients in partial remission prior to transplant. Escalon et al. [8] noted a 3-year OS of $43 \%$ and progression-free survival of $39 \%$, with $60 \%$ of patients in complete 
Table 3. Proportional hazard modeling of prognostic factors affecting survival.

\begin{tabular}{|c|c|c|c|c|c|c|}
\hline \multirow{2}{*}{ Prognostic Factors } & \multicolumn{3}{|c|}{ OS } & \multicolumn{3}{|c|}{ DFS } \\
\hline & HR & $95 \%$ CI & $\mathbf{P}$ & HR & $95 \%$ CI & $\mathbf{P}$ \\
\hline Allogeneic vs. autologous & 0.52 & $0.09-3.11$ & 0.47 & 0.66 & $0.13-3.36$ & 0.62 \\
\hline \multicolumn{7}{|l|}{ Stage } \\
\hline III vs. II & 0.3 & $0.02-4.92$ & 0.4 & 0.3 & $0.02-4.96$ & 0.4 \\
\hline IV vs. II & 0.64 & $0.07-5.97$ & 0.69 & 0.75 & $0.09-6.69$ & 0.8 \\
\hline III/IV vs. II & 0.52 & $0.06-4.67$ & 0.56 & 0.6 & $0.07-5.20$ & 0.65 \\
\hline Chemotherapy-resistant disease & 6.54 & $0.76-56.3$ & 0.09 & 7.73 & $0.93-64.5$ & 0.07 \\
\hline IPI (continuous) & 4.39 & $1.48-13.1$ & 0.008 & 3.01 & $1.15-7.92$ & 0.03 \\
\hline Bulky disease & 0.97 & $0.11-8.34$ & 0.98 & 0.77 & $0.09-6.45$ & 0.81 \\
\hline Age (continuous) & 1.07 & $1.00-1.15$ & 0.06 & 1.06 & $1.00-1.13$ & 0.06 \\
\hline $\begin{array}{c}\text { Gender: } \\
\text { Male vs. Female }\end{array}$ & 1.08 & $0.20-5.92$ & 0.93 & 1.3 & $0.25-6.72$ & 0.75 \\
\hline Number of extra nodal sites $>3$ & 2.47 & $0.45-13.57$ & 0.3 & 2.03 & $0.39-10.51$ & 0.4 \\
\hline Number of prior regimens $>3$ & 0.51 & $0.09-2.84$ & 0.45 & 0.41 & $0.08-2.13$ & 0.29 \\
\hline Performance status 2 - 4 & 3.74 & $0.99-14.0$ & 0.05 & 6.5 & $0.8-53.8$ & 0.08 \\
\hline Baseline liver function $^{*}$ & 1.55 & $0.28-8.62$ & 0.62 & 2.29 & $0.50-10.34$ & 0.29 \\
\hline Baseline cardiac function $^{*}$ & 0.55 & $0.10-2.99$ & 0.49 & 0.47 & $0.09-2.41$ & 0.36 \\
\hline Baseline pulmonary function $^{*}$ & 1.42 & $0.28-7.24$ & 0.67 & 1.05 & $0.23-4.79$ & 0.95 \\
\hline \multicolumn{7}{|l|}{ Pre-SCT LDH } \\
\hline 1 - 3 normal & 15.03 & $1.64-138.08$ & 0.02 & 8.05 & $1.44-45.18$ & 0.02 \\
\hline$\geq 3$ normal & 114.45 & $4.00-3277.54$ & 0.01 & 69.22 & $3.23-1480.45$ & 0.01 \\
\hline
\end{tabular}

Abbreviations: OS, overall survival; DFS, disease-free survival; HR, hazard ratio; CI, confidence interval; P, p-value; IPI, International Prognostic Index; Pre-SCT LDH, LDH immediately prior to transplant. ${ }^{*}$ Analysis involved comparing abnormal versus normal status.

remission/complete remission unconfirmed and $30 \%$ of patients with partial remission prior to transplant, while Copelan et al. [7] noted a 3-year progression free survival of $47 \%$, with $41 \%$ of patients in sensitive-first relapse.

The majority of our patients in the current series had aggressive disease, which was noted by Copelan et al. [7] to be an adverse prognostic factor. Weaver et al. [20] showed that disease stage may be an important determinant of survival outcomes. While disease stage alone did not have a statistically significant impact on survival outcomes in our study, it was factored into the calculated IPI, which we identified as a predictive factor for survival. In addition, several studies have shown that disease status at time of SCT is a critical factor that predicts survival [21,22]. Stiff et al. [22] found that the 3-year OS and PFS of patients with chemotherapy-resistant disease was statistically inferior $(\mathrm{p}=0.009)$ at $29 \%$ and $22 \%$, respectively, in comparison with chemo-sensitive disease patients whose 3 -year OS and PFS were $55 \%$ and $42 \%$, respectively. Gulati et al. [21] found that the DFS of patients who were in complete remission prior to transplant was $80 \%$ in comparison with $11 \%$ for those patients who had progressive disease. Nearly $50 \%$ of patients in our series had chemotherapy-resistant disease at time of SCT. Despite these high-risk features of patients herein, $\mathrm{Bu} /$ $\mathrm{Cy} / \mathrm{VP}-16$ appeared to mitigate this adverse prognostic factor.

Our study was limited by sample size and follow-up. Other investigators have estimated the 4 - 5 years survival of patients with NHL to be approximately $50 \%[6,15,23]$, although Zhang et al. [24] noted a 5-year survival rate of $64 \%$, so further longitudinal analysis of our population is needed to determine whether the pre-transplant characteristics we have identified (lower baseline IPI and normal pre-transplant LDH) continue to confer a survival advantage in the long-term. This will be critical not only for observation of potential disease relapse, but also re- 
garding the development of late effects, in particular the second malignancies/leukemia.

The early TRM with Bu/Cy/VP-16 in our study was $16 \%$. This overall result compares favorably with the $46 \%$ TRM noted by Vaughan et al. [13]. The majority of patients in our series with TRM died due to sepsis and/or hypoxemic respiratory failure, which has been described $[8,23]$. Mucositis also occurred frequently in the early post-transplant period, which has been noted by other authors [7-9,25]. Hepatic toxicity was commonly seen in the initial pre-transplant period, which was also noted by Kim et al. [10] and Copelan et al. [7]. However, venoocclusive disease was rare in our population $(n=1)$; although more cases have been noted in the literature $[10$, 13]. This may be due to intravenous administration of etoposide as opposed to oral dosing, as suggested by Kayshap et al. [26].

Pneumonitis was a common late toxicity, which has previously been described with this regimen [9,27]. Crilley et al. [28] noted significant pulmonary toxicity with this regimen in patients who had received prior radiation, but Spitzer et al. [29] found no difference in pulmonary toxicity between patients receiving total body irradiation and busulfan in combination with etoposide; the pulmonary toxicity noted in our population may therefore be a consequence of busulfan [30]. Given the prevalence of this toxicity, alternative regimens may be considered in those patients with poor baseline pulmonary function, given the risk of long-term disabling pulmonary consequences. Nevertheless, despite these toxicities, there were no late non-relapse fatal events noted (i.e. $>100$ days). Additionally, there were no secondary malignancies or myelodysplasia seen in contrast with Vaughan et al. [13]. This may be due in part to our follow-up time period, and further longitudinal study of our patient population is needed.

Altogether, we conclude that $\mathrm{Bu} / \mathrm{Cy} / \mathrm{VP}-16$ may serve as an effective conditioning regimen for patients with relapsed/refractory NHL. This includes patients with chemotherapy-resistant NHL, including active disease at time of SCT. However, additional analysis and continued refinement of this conditioning regimen are warranted in order to decrease the transplant-related mortality associated with this therapy.

\section{ACKNOWLEDGEMENTS}

The authors would like to acknowledge the Northwestern University Feinberg School of Medicine and the Robert H. Lurie Comprehensive Cancer Center.

\section{REFERENCES}

[1] Haioun, C., Lepage, E., Gisselbrecht, C., Salles, G., Coiffier, B., Brice, P., et al. (2000) Survival benefit of high- dose therapy in poor-risk aggressive non-Hodgkin's lymphoma: Final analysis of the prospective LNH87-2 protocol - a groupe d'Etude des lymphomes de l'Adulte study. Journal of Clinical Oncology, 18, 3025-3030. PMid:10944137.

[2] Milpied, N., Deconinck, E., Gaillard, F., Delwail, V., Foussard, C., Berthou, C., et al. (2004) Initial treatment of aggressive lymphoma with high-dose chemotherapy and autologous stem-cell support. New England Journal of Medicine, 350, 1287-1295. http://dx.doi.org/10.1056/NEJMoa031770

[3] Pettengell, R., Radford, J.A., Morgenstern, G.R., Scarffe, J.H., Harris, M., Woll, P.J., et al. (1996) Survival benefit from high-dose therapy with autologous blood progenitor-cell transplantation in poor-prognosis non-Hodgkin's lymphoma. Journal of Clinical Oncology, 14, 586-592. PMid:8636775.

[4] Philip, T., Guglielmi, C., Hagenbeek, A., Somers, R., Van der Lelie, H., Bron, D., et al. (1995) Autologous bone marrow transplantation as compared with salvage chemotherapy in relapses of chemotherapy-sensitive non-Hodgkin's lymphoma. New England Journal of Medicine, 333, 1540-1545.

http://dx.doi.org/10.1056/NEJM199512073332305

[5] Vose, J.M., Armitage, J.O., Bierman, P.J., Weisenburger, D.D., Hutchins, M., Dowling, M.D., et al. (1989) Salvage therapy for relapsed or refractory non-Hodgkin's lymphoma utilizing autologous bone marrow transplantation. The American Journal of Medicine, 87, 285-288. http://dx.doi.org/10.1016/S0002-9343(89)80152-4

[6] Aggarwal, C., Gupta, S., Vaughan, W.P., Saylors, G.B., Salzman, D.E., Katz, R.O., et al. (2006) Improved outcomes in intermediate- and high-risk aggressive nonHodgkin lymphoma after autologous hematopoietic stem cell transplantation substituting intravenous for oral busulfan in a busulfan, cyclophosphamide, and etoposide preparative regimen. Biology of Blood and Marrow Transplantation, 12, 770-777. http://dx.doi.org/10.1016/j.bbmt.2006.03.016

[7] Copelan, E.A., Penza, S.L., Pohlman, B., Avalos, B.R., Goormastic, M., Andresen, S.W., et al. (2000) Autotransplantation following busulfan, etoposide and cyclophosphamide in patients with non-Hodgkin's lymphoma. Bone Marrow Transplant, 25, 1243-1248.

http://dx.doi.org/10.1038/sj.bmt.1702433

[8] Escalón, M.P., Stefanovic, A., Venkatraman, A., Pereira, D., Santos, E.S., Goodman, M., et al. (2009) Autologous transplantation for relapsed non-Hodgkin's lymphoma using intravenous busulfan and cyclophosphamide as conditioning regimen: A single center experience. Bone Marrow Transplant, 44, 89-96.

http://dx.doi.org/10.1038/bmt.2008.429

[9] Hänel, M., Kröger, N., Sonnenberg, S., Bornhäuser, M., Krüger, W., Kroschinsky, F., et al. (2002) Busulfan, cyclophosphamide, and etoposide as high dose conditioning regimen in patients with malignant lymphoma. Annals of Hematology, 81, 96-102. http://dx.doi.org/10.1007/s00277-001-0413-8

[10] Kim, J.G., Sohn, S.K., Chae, Y.S., Yang, D.H., Lee, J.J., Kim, H.J., et al. (2007) Multicenter study of intravenous 
busulfan, cyclophosphamide, and etoposide (i.v. $\mathrm{Bu} / \mathrm{Cy} / \mathrm{E}$ ) as conditioning regimen for autologous stem cell transplantation in patients with non-Hodgkin's lymphoma. Bone Marrow Transplant, 40, 919-924.

http://dx.doi.org/10.1038/sj.bmt.1705841

[11] Kim, J.E., Lee, D.H., Yoo, C., Kim, S., Kim, S.W., Lee, J.S., et al. (2011) BEAM or BuCyE high-dose chemotherapy followed by autologous stem cell transplantation in non-Hodgkin's lymphoma patients: A single center comparative analysis of efficacy and toxicity. Leukemia Research, 35, 183-187.

http://dx.doi.org/10.1016/j.leukres.2010.07.016

[12] Kröger, N., Hoffknecht, M., Dreger, P., Krüger, W., Zeller, W., Krüll, A., et al. (1998) Long-term disease-free survival of patients with advanced mantle-cell lymphoma following high-dose chemotherapy. Bone Marrow Transplant, 21, 55-57. http://dx.doi.org/10.1038/sj.bmt.1701033

[13] Vaughan, W.P., Dennisone, J.D., Reed, E.C., Klassen, L., McGuire, T.R., Sanger, W.G., et al. (1991) Improved results of allogeneic bone marrow transplantation for advanced hematologic malignancy using busulfan, cyclophosphamide and etoposide as cytoreductive and immunosuppressive therapy. Bone Marrow Transplant, 8, 489495. PMid:1790429.

[14] Bolwell, B., Kalaycio, M., Andresen, S., Goormastic, M., McBee, M., Kuczkowski, E., et al. (2000) Autologous peripheral blood progenitor cell transplantation for transformed diffuse large-cell lymphoma. Clinical Lymphoma, 1, 226-233. http://dx.doi.org/10.3816/CLM.2000.n.019

[15] Kröger, N, Hoffknecht, M., Dreger, P., Krüger, W., Zeller, W., Krüll, A., et al. (1998) Long-term disease-free survival of patients with advanced mantle-cell lymphoma following high-dose chemotherapy. Bone Marrow Transplant, 21, 55-57. http://dx.doi.org/10.1038/sj.bmt.1701033

[16] Philip, T., Armitage, J.O., Spitzer, G., Chauvin, F., Jagannath, S., Cahn, J., et al. (1987) High-dose therapy and autologous bone marrow transplantation after failure of conventional chemotherapy in adults with intermediategrade or high-grade non-Hodgkin's lymphoma. New England Journal of Medicine, 316, 1493-1498. http://dx.doi.org/10.1056/NEJM198706113162401

[17] Schouten, H.C., Colombat, P., Verdonck, L.F., Gorin, N.C., Björkstrand, B., Taghipour, G., et al. (1994) Autologous bone marrow transplantation for low-grade nonHodgkin's lymphoma: The European Bone Marrow Transplant Group experience. EBMT Working Party for Lymphoma. Annals of Oncology, 5, 147-149. http://dx.doi.org/10.1093/annonc/5.suppl_2.S147

[18] Sweetenham, J.W., Proctor, S.J., Blaise, D., De Laurenzi, A., Pearce, R., Taghipour, G., et al. (1994) High-dose therapy and autologous bone marrow transplantation in first complete remission for adult patients with highgrade non-Hodgkin's lymphoma: The EBMT experience. Lymphoma Working Party of the European Group for Bone Marrow Transplantation. Annals of Oncology, 5, 155-159. http://dx.doi.org/10.1093/annonc/5.suppl 2.S155

[19] Takvorian, T., Canellos, G.P., Ritz, J., Freedman, A.S., Anderson, K.C., Mauch, P., et al. (1987) Prolonged dis- ease-free survival after autologous bone marrow transplantation in patients with non-Hodgkin's lymphoma with a poor prognosis. New England Journal of Medicine, 316, 1499-1505.

http://dx.doi.org/10.1056/NEJM198706113162402

[20] Weaver, C.H., Petersen, F.B., Appelbaum, F.R., Bensinger, W.I., Press, O., Martin, P., et al. (1994) High-dose fractionated total body irradiation, etoposide, and cyclophosphamide followed by autologous stem cell support in patients with malignant lymphoma. Journal of Clinical Oncology, 12, 2559-2566. PMid:7989929.

[21] Gulati, S., Yahalom, J., Acaba, L., Reich, L., Motzer, R., Crown, J., et al. (1992) Treatment of patients with relapsed and resistant non-Hodgkin's lymphoma using total body irradiation, etoposide, and cyclophosphamide and autologous bone marrow transplantation. Journal of Clinical Oncology, 10, 936-941.

[22] Stiff, P.J., Dahlberg, S., Forman, S.J., McCall, A.R., Horning, S.J., Nademanee, A.P., et al. (1998) Autologous bone marrow transplantation for patients with relapsed or refractory diffuse aggressive non-Hodgkin's lymphoma: Value of augmented preparative regimens-A Southwest Oncology Group trial. Journal of Clinical Oncology, 16, 48-55.

[23] Santos, E.C., Sessions, J., Hutcherson, D., Flowers, C., Langston, A. and Waller EK. (2007) Long-term outcome of Hodgkin disease patients following high-dose busulfan, etoposide, cyclophosphamide, and autologous stem cell transplantation-A similar experience. Biology of Blood and Marrow Transplantation, 13, 746-747.

http://dx.doi.org/10.1016/j.bbmt.2007.02.006

[24] Zhang, H., Graiser, M., Hutcherson, D.A., Olufemi Dada, M., McMillan, S., Zahir, A., et al. (2012) Pharmacokinetic-directed high dose busulfan combined with cyclophosphamide and etoposide results in predictable drug levels and durable long term survival in lymphoma patients undergoing autologous stem cell transplantation. Biology of Blood and Marrow Transplant, 18, 1287-1294. http://dx.doi.org/10.1016/j.bbmt.2012.02.006

[25] Ritchie, D.S., Szer, J., Roberts, A.W., Shuttleworth, P. and Grigg, A.P. (2002) A phase I dose-escalation study of etoposide continuous infusion added to busulphan/cyclophosphamide as conditioning prior to autologous or allogeneic stem cell transplantation. Bone Marrow Transplantation, 30, 645-650. http://dx.doi.org/10.1038/sj.bmt.1703698

[26] Kashyap, A., Wingard, J., Cagnoni, P., Roy, J., Tarantolo, S., Hu, W., et al. (2002) Intravenous versus oral busulfan as part of a busulfan/cyclophosphamide preparative regimen for allogeneic hematopoietic stem cell transplantation: Decreased incidence of hepatic venoocclusive disease (HVOD), HVOD-related mortality, and overall 100day mortality. Biology of Blood and Marrow Transplantation, 8, 493-500. http://dx.doi.org/10.1053/bbmt.2002.v8.pm12374454

[27] Wadehra, N., Farag, S., Bolwell, B., Elder, P., Penza, S., Kalaycio, M., et al. (2006) Long-term outcome of Hodgkin disease patients following high-dose busulfan, etoposide, cyclophosphamide, and autologous stem cell transplantation. Biology of Blood and Marrow Transplan- 
tation, 12, 1343-1349.

http://dx.doi.org/10.1016/j.bbmt.2006.08.039

[28] Crilley, P., Topolsky, D., Styler, M.J., Bernstein, E., Resnick K, Mullaney, R., et al. (1995) Extramedullary toxicity of a conditioning regimen containing busulphan, cyclophosphamide and etoposide in 84 patients undergoing autologous and allogenic bone marrow transplantation. Bone Marrow Transplantation, 15. 361-365.

PMid:7599559

[29] Spitzer, T.R., Cottler-Fox, M., Torrisi, J., Cahill, R.,
Greenspan, A., Lynch, M., et al. (1989) Escalating doses of etoposide with cyclophosphamide and fractionated total body irradiation or busulfan as conditioning for bone marrow transplantation. Bone Marrow Transplantation, 4, 559-565. PMid:2676044.

[30] Kalaycio, M., Pohlman, B., Kuczkowski, E., Rybicki, L., Andresen, S., Sobecks, R., et al. (2006) High-dose busulfan and the risk of pulmonary mortality after autologous stem cell transplant. Clinical Transplantation, 20, 783787. http://dx.doi.org/10.1111/j.1399-0012.2006.00581.x 